\title{
Flavocytochrome $b_{2}$-Based Enzymatic Method of L-Lactate Assay in Food Products
}

\author{
Oleh Smutok, ${ }^{1}$ Maria Karkovska, ${ }^{1}$ Halyna Smutok, ${ }^{1}$ and Mykhailo Gonchar ${ }^{1,2}$ \\ ${ }^{1}$ Department of Analytical Biothecnology, Institute of Cell Biology, Drahomanov Street 14/16, Lviv 79005, Ukraine \\ ${ }^{2}$ Institute of Applied Biotechnology and Basic Sciences, University of Rzeszow, Sokolowska Street 26, 36-100 Kolbuszowa, Poland
}

Correspondence should be addressed to Mykhailo Gonchar; gonchar@cellbiol.lviv.ua

Received 6 August 2013; Accepted 28 August 2013

Academic Editors: M. Ben Ali, K. Moriya, and T. M. Wu

Copyright (C) 2013 Oleh Smutok et al. This is an open access article distributed under the Creative Commons Attribution License, which permits unrestricted use, distribution, and reproduction in any medium, provided the original work is properly cited.

L-lactate, a key metabolite of the anaerobic glycolytic pathway, plays an important role as a biomarker in medicine, in the nutritional sector and food quality control. For these reasons, there is a need for very specific, sensitive, and simple analytical methods for the accurate L-lactate measuring. A new highly selective enzymatic method for L-lactate determination based on the use of flavocytochrome $b_{2}$ (EC 1.1.2.3; FC $b_{2}$ ) isolated from the recombinant strain of the yeast Hansenula polymorpha has been developed. A proposed enzymatic method exploits an enzymatic oxidation of L-lactate to pyruvate coupled with nitrotetrazolium blue (NTZB) reduction to a colored product, formazan. The maximal absorption peak of the colored product is near $\lambda=525 \mathrm{~nm}$ and the linear range is observed in the interval $0.005-0.14 \mathrm{mM}$ of L-lactate. The main advantages of the proposed method when compared to the LDH-based routine approaches are a higher sensitivity $(2.0 \mu \mathrm{M}$ of L-lactate), simple procedure of analysis, usage of inexpensive, nontoxic reagents, and small amount of the enzyme. Enzymatic oxidation of L-lactate catalyzed by flavocytochrome $b_{2}$ and coupled with formazan production from nitrotetrazolium blue was shown to be used for L-lactate assay in food samples. A high correlation between results of the proposed method and reference ones proves the possibility to use flavocytochrome $b_{2}$-catalysed reaction for enzymatic measurement of L-lactate in biotechnology and food chemistry.

\section{Introduction}

Lactic acid is a universal metabolite of nearly all living organisms and a natural or artificial component of many food products. An accurate quantitative determination of L-lactate is very important for fermentation industries, online control of the quality of alcoholic beverages [1], and sour milk products [2]. Moreover, detection of L-lactate is important for control of the quality of food which contain lactate salts or free acid as $\mathrm{pH}$-stabilizing additive and preservative (especially in meat's products for growth reducing the some pathogenic bacteria like Listeria monocytogenes) [3]. The increase of lactate concentration in some technological processes can be a result of microbial contamination [4]; therefore, a precise lactate assay is necessary for detection of early stages of such processes. In addition, many cosmetics, pharmaceuticals, domestic washing powders, and antiseptic goods contain this compound [5]. A level of L-lactate content in human blood is an important clinical indicator of hypoxia, acidosis [6], and level of drug's toxicity [7] and serves as a marker for evaluation of the optimal sportsmen's training [8]. L-lactate is also an important biomarker for different types of cancer due to Warburg phenomenon [9].

For an assay of L-lactate, a lot of physicochemical and chemical methods have been proposed: spectrophotometry [10], fluorometry [11], $\mathrm{pH}$ potentiometric measurements [12], and amperometric biosensors based on $\mathrm{O}_{2}$ and $\mathrm{H}_{2} \mathrm{O}_{2}$ electrodes [13]. Most of these methods require a lot of time and previous labor-consuming procedures such as filtration, chromatography, and deproteinization. On the other hand, most of them require expensive equipment or are nonselective.

Enzyme-based spectrophotometric assay of L-lactate is widely used due to the favorable sensitivity of biorecognizing compounds and simple procedure of analysis. Among available methods for the determination of L-lactate by enzymatic 
spectrophotometric approaches, the most exploited are the methods with the use of $\mathrm{NAD}^{+}$-dependent lactate dehydrogenase (LDH) from animal muscles or heart (EC 1.1.1.27) [14] or bacterial lactate oxidase (LOX) (EC 1.13.12.4) [15]. Weak points of LDH-based approaches are high price of the enzyme and coenzyme and nonsufficient selectivity. Moreover, $\mathrm{NAD}^{+}$-dependent $\mathrm{LDH}$ equilibrium is not optimal for L-Lactate assay, so the reaction of the product (pyruvate) with toxic compounds, for example, hydrazine or hydroxylamine, or the use of an additional enzyme such as glutamate-pyruvate transaminase (GPT) is necessary to shift the equilibrium to the product side [16]. On the other hand, elimination of reverse effects could be performed by higher $\mathrm{pH}$ value and $\mathrm{NAD}^{+}$content [17]. The imperfections of LOX-based methods of L-lactate analysis are their expensiveness and interference at a high protein content in the analyzed samples [15].

Besides LDL and LO, another enzyme is known for participating in the lactic acid metabolism in yeast, namely, Llactate-cytochrome $c$ oxidoreductase (EC 1.1.2.3; flavocytochrome $b_{2}, \mathrm{FC} b_{2}$ ) [18] which catalyses the electron transfer from L-lactate to cytochrome cin yeast mitochondria. The protein from Saccharomyces cerevisiae and Hansenula anomala is a tetramer with four identical subunits, each consisting of FMN- and heme-binding domains [19]. FC $b_{2}$ has absolute specificity for L-lactate; moreover, it functions in vitro with no regard to the nature of electron acceptors which makes this enzyme very promising for analytical biotechnology.

In this paper, we describe a new enzymatic method for L-lactate assay based on the use of a purified FC $b_{2}$, isolated from the recombinant strain of the thermotolerant yeast Hansenula polymorpha, coupled with phenazine-mediated reduction of nitrotetrazolium salt to photometrically detected colored formazan product. Recently, we have reported about the development of a highly selective method/kit for L-lactate analysis based on FC $b_{2}$-dependent enzymatic transformation of L-lactate coupled with nonenzymatic generation of dissolved form of Prussian Blue at the presence of specific solubilizer $[20,21]$. Moreover, possibility of FC $b_{2}$ using as L-lactate selective element in biosensor technology has been successfully proved by us previously $[22,23]$.

The aim of the work is using flavocytochrome $b_{2}$-catalyzed reaction for L-lactate assay in food products. The peculiarity of the proposed bioanalytic method is its high selectivity, usage of inexpensive and nontoxic reagents that provide a simple, accurate assay procedure and a low price of the analysis. It is worth to mention that contrary to a very unstable $S$. cerevisiae-derived enzyme, FC $b_{2}$ for thermotolerant species $H$. polymorpha is stable and better fits the analytical purposes.

\section{Material and Methods}

2.1. Materials . DEAE-Toyopearl 650M was obtained from Toyo Soda (Tokyo, Japan). EDTA and nitrotetrazolium blue (NTZB) were from Merck (Darmstadt, Germany). L(+)-Lactic acid was from Acros Organics (Geel, Belgium). Sodium Llactate and $\mathrm{LDH}$ from bovine heart (EC 1.1.1.27) were purchased from Sigma-Aldrich Corporation (Deisenhofen, Germany), Triton X-100 from Fluka (Buchs, Switzerland), and $\mathrm{NAD}^{+}$and $\mathrm{NADH}$ were obtained from Gerbu Biotechnik
(Gailberg, Germany), LOX-based sensor from SensLab $\mathrm{GmbH}$ (Leipzig, Germany). All chemicals and reagents were of analytical grade and all solutions were prepared using HPLC-grade water. L-lactate standard solution and appropriate dilutions were prepared in $100 \mathrm{mM}$ phosphate buffer, pH 7.8.

2.2. Isolation and Purification of L-Lactate Cytochrome c Oxidoreductase $\left(F C b_{2}\right)$. The recombinant strain trl of the thermotolerant yeast Hansenula polymorpha possessing enzyme with a specific activity up to $11 \mathrm{U} \cdot \mathrm{mg}^{-1}$ in cell-free extracts [29] was used as a source of FC $b_{2}$. Enzyme was isolated by ion-exchange chromatography on DEAE-Toyopearl cellulose $650 \mathrm{M}$ [18]. The purified enzyme was stored as a suspension in $70 \%$-saturated ammonium sulfate at $-10^{\circ} \mathrm{C}$ before using.

2.3. Assay of $\mathrm{FC} b_{2}$ Activity. One unit of the FC $b_{2}$ activity is defined as that amount of the enzyme which forms $1 \mu \mathrm{mol}$ hexacyanoferrate(II) per minute under standard conditions of the assay $\left(20^{\circ} \mathrm{C}, 30 \mathrm{mM}\right.$ phosphate buffer, $\left.\mathrm{pH} 7.8\right)$. Activity was estimated by spectrophotometric monitoring of hexacyanofer rate(III) reduction at $\lambda=420 \mathrm{~nm}$. During this process, optical density of the analyzed solution becomes lower. Assay mixture consisted of $30 \mathrm{mM}$ phosphate buffer, $\mathrm{pH} 8.0,33 \mathrm{mM}$ sodium L-lactate, $1 \mathrm{mM}$ EDTA, and $83 \mathrm{mM}$ $\mathrm{K}_{3} \mathrm{Fe}(\mathrm{CN})_{6}$.

The specific activity of $\mathrm{FC} b_{2}$ was calculated by formula:

$$
\mathrm{SA}=\frac{\Delta E / \min \cdot V \cdot n}{\mathscr{E}_{\mathrm{mM}} \cdot C p \cdot V_{E}},
$$

where $\Delta E / \mathrm{min}$-change of optical density at $\lambda=420 \mathrm{~nm}$ per min; $V$-total volume of the assay solution, $\mathrm{mL} ; n$-dilution of the enzyme before assay; $\mathscr{E}_{\mathrm{mM}}$-millimolar extinction of hexacyanoferrate(III), $1.04 \mathrm{mM}^{-1} \cdot \mathrm{cm}^{-1} ; V_{E}$-volume of the added enzyme aliquot, $\mathrm{mL}$; $C p$-protein concentration of the tested FC $b_{2}$ solution determined by the Lowry method, $\mathrm{mg} \cdot \mathrm{mL}^{-1}$.

2.4. Enzymatic Assay of L-Lactate. Optimized reaction mixture consisted of $50 \mathrm{mM}$ phosphate buffer, $\mathrm{pH} 7.8 ; 1.5 \mathrm{mM}$ phenazine methosulfate; $0.1 \%$ nitrotetrazolium blue; $1 \%$ Triton X-100; $0.5 \mathrm{U} \cdot \mathrm{mL}^{-1} \mathrm{FC} b_{2}$. The assay was carried out in the dark at $25^{\circ} \mathrm{C}$. The reaction was started by adding $0.2 \mathrm{~mL}$ analyzed sample into a glass test tube with $0.8 \mathrm{~mL}$ reaction mixture. Photometric measurements were carried out on spectrophotometer SHIMADZU UV-1650 PC at $525 \mathrm{~nm}$ in plastic cuvette after incubation of the samples during $20 \mathrm{~min}$ in the dark. The blank sample consisted of all reagents, except lactate (water was added instead of analyzed sample). The reaction was terminated by adding $3 \mathrm{~mL}$ of $0.3 \mathrm{M} \mathrm{HCl}$. The calibration was carried out using standard solution of L-lactate $(60 \mathrm{mM})$ in 40 -fold dilutions.

2.5. Preparation of Food Products and Wines. The milk samples were mixed with $4 \%$ trichloroacetic acid (final concentration). The supernatants were neutralized by $1 \mathrm{M} \mathrm{KOH}$ and used for analysis. The ketchup samples were diluted with 
TABLE 1: Bioanalytical characteristics of different methods of L-lactate assay (calculated for concentrations in the final reaction mixture).

\begin{tabular}{lccccc}
\hline Enzymatic methods & $\lambda_{\max }, \mathrm{nm}$ & $E, \mathrm{mM}^{-1} \mathrm{~cm}^{-1}$ & Detection limit, $\mu \mathrm{M}$ & Linear range, $\mathrm{mM}$ & Time of analysis, min \\
\hline LDH-GPT based [24] & 340 & 6.3 & 3.37 & $0.033-0.39$ & 30 \\
Flavocytochrome $b_{2}$-based [20] & 680 & 5.0 & 3.0 & $0.008-0.27$ & 30 \\
LO: peroxidase; ABTS based [25] & 405 & 34 & - & $0.002-0.068$ & 30 \\
LDH based [14] & 340 & 6.3 & 5.6 & $0.025-0.16$ & 30 \\
Lactate oxidase and aminoantipyrine based [26] & 546 & 38 & - & $0.0003-0.099$ & 10 \\
Current method & 525 & 12 & 2.0 & $0.005-0.14$ & 20 \\
\hline
\end{tabular}

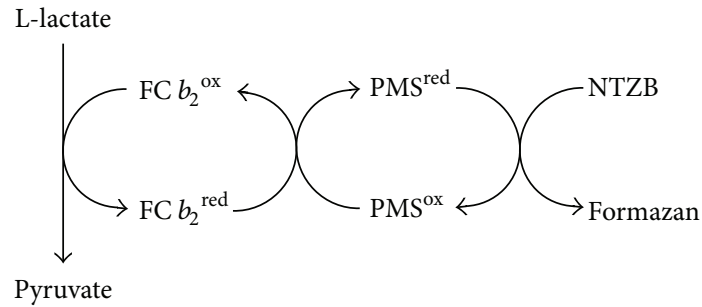

FIGURE 1: The scheme of the reactions exploited in enzymatic assay of L-lactate.

distilled water and filtrated through $0.2 \mu \mathrm{m}$ pores microfilter Minisart NML SM $16534 \mathrm{~K}$ (Sartorius GmbH, Gottingen, Germany). The wine samples were diluted for 50 times by distilled water. Additional treatment of the wine and juices samples was omitted.

\section{Results and Discussion}

3.1. Development of an Enzymatic L-Lactate Assay. The procedure is based on FC $b_{2}$-catalyzed oxidation of L-lactate to pyruvate. Different mediators (hexacyanoferrate(III), methylene blue, phenazine ethosulfate, and phenazine methosulfate) were tested to provide an optimal electron transfer from the reduced enzyme to nitrotetrazolium blue (NTZB). Phenazine methosulfate (PMS) was chosen as the best mediator (data not shown). To provide solubilization of the formed formazan, a detergent Triton X-100 in 1\% final concentration was used. The principle of the proposed method is shown in Figure 1.

The optimal conditions for NTZB reduction to colored product formazan were investigated. An optimal time of incubation duration at temperature $20-25^{\circ} \mathrm{C}$ is about $20 \mathrm{~min}$ for the activity of $\mathrm{FC} b_{2}$ in reaction mixture $0.5 \mathrm{U} \cdot \mathrm{mL}^{-1}$. The maximal absorption of the reduction product was observed at $525 \mathrm{~nm}$ at acidic conditions.

As shown in Figure 2, formazan formation is linearly dependent on the concentration of L-lactate in the reaction mixture up to $0.14 \mathrm{mM}$. In the indicated concentration range, the formazan product which has usually a low solubility was not precipitated (in the presence of Triton X-100). Optical density of the reaction mixture after adding $\mathrm{HCl}$ was stable for several days (in the dark).

The proposed method has the next operational parameters: limit of assay-about $2 \mu \mathrm{M}$ of L-lactate (in final photometred mixture); linear range-up to $0.14 \mathrm{mM}$ of L-lactate.
The analytical parameters of the proposed enzymatic method in comparison with the known approaches are presented in Table 1.

To estimate the level of the analyte transformation to the final product, additional calibration using NADH as a reducing agent for NTZB was carried out. For this procedure, conditions were the same as for L-lactate assay, except for the addition of FC $b_{2}$. The precise concentration of NADH standard solution was calculated by measuring its optical density at $340 \mathrm{~nm}\left(\mathscr{E}_{\mathrm{mM}}=6.23 \mathrm{mM}^{-1} \cdot \mathrm{cm}^{-1}\right)$. Calibration curve for NADH in PMS-NTZB-formazan reaction is shown in Figure 3.

On the base of molar extinction of formazan product calculated from calibration data obtained in reaction $\mathrm{NADH}+$ PMS + NTZB, the enzymatic conversion of the analyte under the used conditions was about $40 \%$ that is in a good correlation with units of $\mathrm{FC} b_{2}$ activity added to reaction mixture.

3.2. Assay of L-Lactate in Some of Food Products and Wine. The developed method was tested on samples of food products(milk, ketchup, and juice). The results obtained by this approach have been compared with the reference methods: biosensor analysis using SensLab biosensor [27], $\mathrm{NAD}^{+}$dependent LDH spectrophotometric method [28], and Prussian Blue generation [20,21] (Table 2).

Generally, the obtained results of L-lactate analysis in food products are in a good correlation with the compared methods that confirms the correctness of lactate assay by the developed approach.

The content of L-lactate in wine samples was also analyzed by SensLab-biosensor [27] and FC $b_{2}$-based method [20, 21]. The obtained analytical results were compared with L-lactate content declared by a producer. The wine samples Cabernet Sauvignon, Chardonnay, and Sherry Strong received from Magarach winery (the Crimea, Ukraine) were used for such experiments (Table 3 ).

The significant difference between L-lactate content in the wine Chardonnay declared by the producer and obtained by biosensor and current FC $b_{2}$-based method could be explained by a low selectivity of the routine used in winery (low-resolution ion-exchange chromatography coupled with colorimetric) analysis.

\section{Conclusions}

A new enzymatic method for L-lactate analysis has been proposed. The method is based on enzymatic oxidation of $\mathrm{L}$ lactate to pyruvate in the presence of flavocytochrome $b_{2}$ coupled with nitrotetrazolium blue reduction to colored product, 
TABLE 2: Comparison of the results of L-lactate assay (in $\mathrm{mM}$ ) in food products.

\begin{tabular}{|c|c|c|c|c|}
\hline \multirow{2}{*}{ Sample } & \multicolumn{4}{|c|}{ Method } \\
\hline & $\begin{array}{c}\text { SensLab biosensor } \\
\text { [27] }\end{array}$ & $\begin{array}{c}\text { FC } b_{2} \text {-based method } \\
{[20,21]}\end{array}$ & $\mathrm{NAD}^{+}$-LDH-based method [28] & Current method \\
\hline Rewe Milk ( $0.3 \%$ fat) & $\begin{array}{l}0.21 \pm 0.02 \\
P>0.05^{* *}\end{array}$ & $\begin{array}{l}0.20 \pm 0.05 \\
P>0.05^{* *}\end{array}$ & $\begin{array}{c}0.278 \pm 0.03 \\
P<0.05^{*}\end{array}$ & $0.192 \pm 0.002$ \\
\hline Milsani Milk (1.5\% fat) & $\begin{array}{l}0.16 \pm 0.04 \\
P>0.05^{* *}\end{array}$ & $\begin{array}{c}0.179 \pm 0.006 \\
P>0.05^{* *}\end{array}$ & $\begin{array}{l}0.26 \pm 0.33 \\
P<0.05^{*}\end{array}$ & $0.172 \pm 0.01$ \\
\hline Rich Ketchup & $\begin{array}{l}1.43 \pm 0.35 \\
P>0.05^{* *}\end{array}$ & $\begin{array}{l}1.36 \pm 0.02 \\
P>0.05^{* *}\end{array}$ & $\begin{array}{l}1.64 \pm 0.11 \\
P>0.05^{* *}\end{array}$ & $1.46 \pm 0.4$ \\
\hline Maitre Ketchup & $\begin{array}{c}0.62 \pm 0.129 \\
P>0.05^{* *}\end{array}$ & $\begin{array}{l}0.78 \pm 0.01 \\
P>0.05^{* *}\end{array}$ & $\begin{array}{c}1.08 \pm 0.04 \\
P>0.05^{* *}\end{array}$ & $0.74 \pm 0.02$ \\
\hline Krings Apple juice $100 \%$ & $\begin{array}{l}0.15 \pm 0.014 \\
P>0.05^{* *}\end{array}$ & $\begin{array}{l}0.14 \pm 0.04 \\
P>0.05^{* *}\end{array}$ & $\begin{array}{c}0.256 \pm 0.05 \\
P<0.05^{*}\end{array}$ & $0.16 \pm 0.015$ \\
\hline Belsina Apple drink (50\%) & $\begin{array}{l}0.14 \pm 0.001 \\
P>0.05^{* *}\end{array}$ & $\begin{array}{l}0.132 \pm 0.01 \\
P>0.05^{* *}\end{array}$ & $\begin{array}{c}0.285 \pm 0.07 \\
P<0.05^{*}\end{array}$ & $0.135 \pm 0.01$ \\
\hline
\end{tabular}

${ }^{*}$ Difference between current method and the compared methods is statistically significant.

${ }^{* *}$ Difference between current method and other methods is statistically insignificant.

TABLE 3: Comparison of the results of L-lactate assay (in $\mathrm{g} \cdot \mathrm{L}^{-1}$ ) in wine samples.

\begin{tabular}{|c|c|c|c|c|}
\hline \multirow{2}{*}{ Sample } & \multicolumn{4}{|c|}{ Method } \\
\hline & $\begin{array}{c}\text { SensLab biosensor } \\
{[27]}\end{array}$ & $\begin{array}{c}\text { FC } b_{2} \text {-based method } \\
{[20,21]}\end{array}$ & Declared by producer & Current method \\
\hline Cabernet Sauvignon (dry red) & $\begin{array}{l}2.4 \pm 0.28 \\
P>0.05^{* *}\end{array}$ & $\begin{array}{l}2.25 \pm 0.18 \\
P>0.05^{* *}\end{array}$ & $\begin{array}{c}2.5 \pm 0.2 \\
P>0.05^{* *}\end{array}$ & $2.15 \pm 0.13$ \\
\hline Chardonnay (dry white) & $\begin{array}{l}1.16 \pm 0.11 \\
P>0.05^{* *}\end{array}$ & $\begin{array}{l}1.03 \pm 0.08 \\
P>0.05^{* *}\end{array}$ & $\begin{array}{l}3.0 \pm 0.2 \\
P<0.05^{*}\end{array}$ & $0.97 \pm 0.12$ \\
\hline Sherry (strong white) & $\begin{array}{l}0.58 \pm 0.05 \\
P>0.05^{* *}\end{array}$ & $\begin{array}{l}0.6 \pm 0.07 \\
P>0.05^{* *}\end{array}$ & $\begin{array}{c}1.1 \pm 0.2 \\
P<0.05^{*}\end{array}$ & $0.49 \pm 0.08$ \\
\hline
\end{tabular}

${ }^{*}$ Difference between current method and the compared methods is statistically significant.

** Difference between current method and other methods is statistically insignificant.

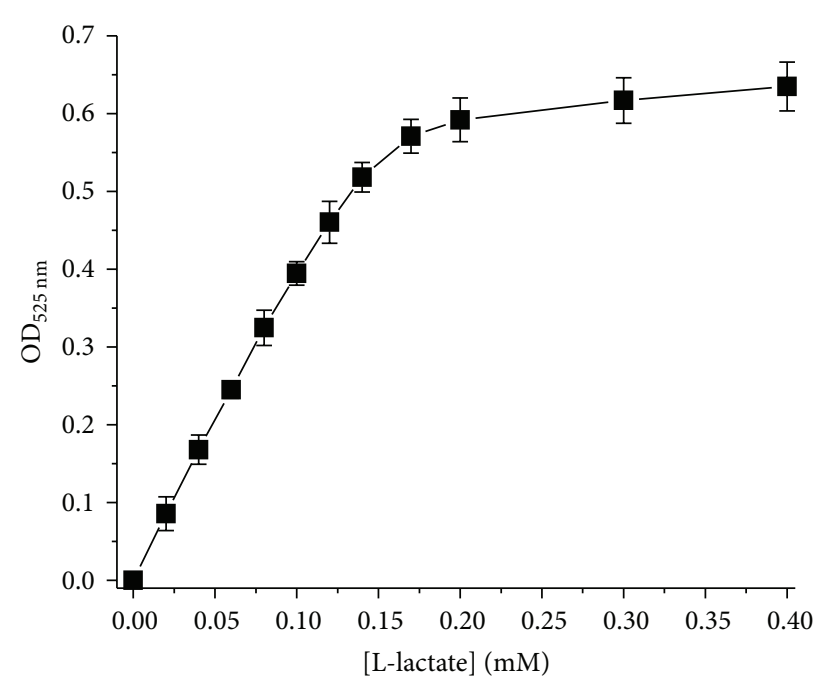

(a)

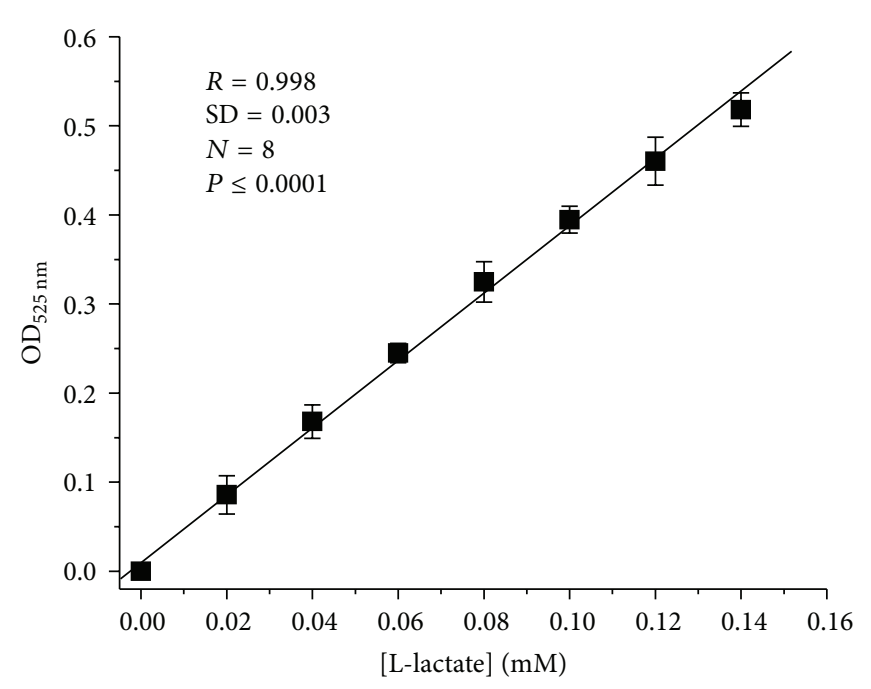

(b)

FIGURE 2: Dependence of optical density of the reaction mixture on L-lactate concentration (a) and a linear range (b) for enzymatic method. Conditions are described in Section 2. 


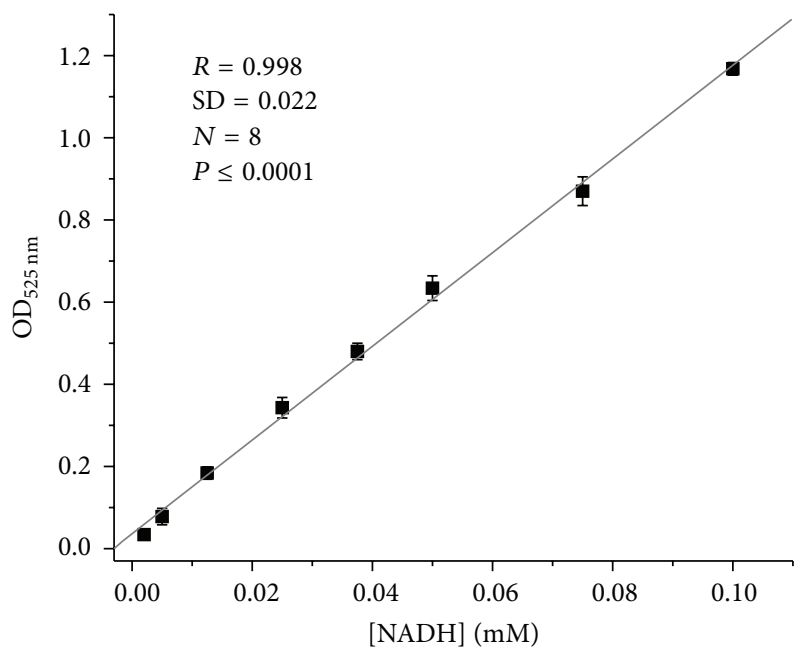

Figure 3: Dependence of optical density of reaction mixture on $\mathrm{NADH}$ concentration.

formazan. Optimal conditions for carrying out correct Llactate analysis have been found. The main advantages of the proposed method when compared to the LDH-based routine approaches are a higher sensitivity $(2.0 \mu \mathrm{M}$ of L-lactate), simple procedure of analysis, and usage of inexpensive, nontoxic reagents and small amount of the enzyme. The method has been used for quantitative determination of L-lactate in food products and wine samples. A good correlation for Llactate analysis between results obtained by current $\mathrm{FC} b_{2}$ based method and other selective analytical methods clearly shows a practical importance of the developed method for biotechnology and food technology.

\section{Acknowledgments}

This work was partially supported by NAS of Ukraine in the frame of the Scientific-Technical Program "Sensor systems for medical, ecological and industrial-technological needs: metrological assurance and research exploitation" and Cross-border Cooperation Program Poland-BelarusUkraine 2007-2013, IPBU.03.01.00-18-452/11-00 "Scientific integration of the Polish-Ukrainian borderland area in the field of monitoring and detoxification of harmful substances in environment".

\section{References}

[1] A. Vilela-Moura, D. Schuller, A. Mendes-Faia et al., "The impact of acetate metabolism on yeast fermentative performance and wine quality: reduction of volatile acidity of grape musts and wines," Applied Microbiology and Biotechnology, vol. 89, no. 2, pp. 271-280, 2011.

[2] A. Londero, R. Quinta, A. G. Abraham, R. Sereno, G. De Antoni, and G. L. Garrote, "Inhibitory activity of cheese whey fermented with kefir grains," Journal of Food Protection, vol. 74, no. 1, pp. 94-100, 2011.

[3] A. Mohan, F. W. Pohlman, J. A. McDaniel, and M. C. Hunt, "Role of peroxyacetic acid, octanoic acid, malic acid, and potassium lactate on the microbiological and instrumental color characteristics of ground beef," Journal of Food Science, vol. 77, no. 4, pp. M188-M193, 2012.

[4] F. Palmisano, M. Quinto, R. Rizzi, and P. G. Zambonin, "Flow injection analysis of L-lactate in milk and yoghurt by online microdialysis and amperometric detection at a disposable biosensor," Analyst, vol. 126, no. 6, pp. 866-870, 2001.

[5] J. C. Hubinger, "A survey of consumer cosmetic products and salon preparations for alpha hydroxy acids," Journal of Cosmetic Science, vol. 53, no. 5, pp. 243-248, 2002.

[6] M. Holzmann, S. Cnattingius, and L. Nordstrim, "Lactate production as a response to intrapartum hypoxia in the growthrestricted fetus," An International Journal of Obstetrics and Gynaecology, vol. 119, no. 10, pp. 1265-1269, 2012.

[7] G. J. Kost, T. H. Nguyen, and Z. Tang, "Whole-blood glucose and lactate. Trilayer biosensors, drug interference, metabolism, and practice guidelines," Archives of Pathology and Laboratory Medicine, vol. 124, no. 8, pp. 1128-1134, 2000.

[8] R. Beneke, R. M. Leithäuser, and O. Ochentel, "Blood lactate diagnostics in exercise testing and training," International Journal of Sports Physiology and Performance, vol. 6, no. 1, pp. 8-24, 2011.

[9] W. H. Koppenol, P. L. Bounds, and C. V. Dang, "Otto Warburg's contributions to current concepts of cancer metabolism," Nature Reviews Cancer, vol. 11, no. 5, pp. 325-337, 2011.

[10] A. N. Araújo, J. L. F. C. Lima, M. L. M. F. S. Saraiva, and E. A. G. Zagatto, "A new approach to dialysis in sequential injection systems: spectrophotometric determination of $\mathrm{L}(+)$-lactate in wines," American Journal of Enology and Viticulture, vol. 48, no. 4, pp. 428-432, 1997.

[11] T. Fukushima, S. Adachi, H. Ichihara, S. Al-Kindy, and K. Imai, "Fluorimetric determination of D- and L-lactate derivatized with 4-(N, N-dimethylaminosulfonyl)-7-piperazino-2, 1, 3-benzoxadiazole (DBD-PZ) by high-performance liquid chromatography," Japan Biomedical Chromatography, vol. 13, pp. 418-424, 1999.

[12] D. Compagnone, A. Mosca, and G. Palleschi, "Cyclic enzymatic determination of L-lactate by differential $\mathrm{pH}$ measurement," Analytical Letters, vol. 28, no. 14, pp. 2475-2490, 1995.

[13] H. Guntermann, K. Herna, M. M. Schindler, and J. G. Schindler, " $\mathrm{O}_{2}$ sensitive L-lactate biosensors with enzyme membranes based on L-lactate-2-monooxygenase and L-lactate-oxidase with electroanalytic comparison," Biomedizinische Technik, vol. 41, no. 10, pp. 268-272, 1996.

[14] J. L. F. C. Lima, T. I. M. S. Lopes, and A. O. S. S. Rangel, "Enzymatic determination of L(+) lactic and L(-) malic acids in wines by flow-injection spectrophotometry," Analytica Chimica Acta, vol. 366, no. 1-3, pp. 187-191, 1998.

[15] D. Bozimowski, J. D. Artiss, and B. Zak, "Sensitive determination of cerebrospinal fluid pyruvate, lactate and glucose concentrations," Clinica Chimica Acta, vol. 153, no. 1, pp. 63-69, 1985.

[16] F. Noll, "Methode zur quantitativen bestimmung von L(+)-lactate mittels lactat-dehydrogenase und Glutamat-pyruvat-transaminase," Biochem Z, vol. 346, pp. 41-49, 1966.

[17] R. J. Maughan, "A simple, rapid method for the determination of glucose, lactate, pyruvate, alanine, 3-hydroxybutyrate and acetoacetate on a single 20- $\mu$ l blood sample," Clinica Chimica Acta, vol. 122, no. 2, pp. 231-240, 1982.

[18] C. A. Appleby and R. K. Morton, "Lactic dehydrogenase and cytochrome $b_{2}$ of baker's yeast; purification and crystallization," The Biochemical Journal, vol. 71, no. 3, pp. 492-499, 1959. 
[19] F. Labeyrie, A. Baudras, and F. Lederer, "[27] Flavocytochrome $b_{2}$ or L-lactate cytochrome $c$ reductase from yeast," Methods in Enzymology, vol. 53, pp. 238-256, 1978.

[20] M. Gonchar, O. Smutok, and H. Os'mak, "Flavocytochrome $b_{2}$ based enzymatic composition, method and kit for L-lactate," US Patent Application PCT/US2008/069637, Pub. No WO/2009/ 009656, 2009.

[21] M. Gonchar, O. Smutok, and H. Os'mak, "Method of quantitative assay of L-lactate in the food products and biological solutions," UA patent 45283. Bul. 21 (Ukrainian), 2009.

[22] O. Smutok, G. Gayda, M. Gonchar, and W. Schuhmann, "A novel L-lactate-selective biosensor based on flavocytochrome $b_{2}$ from methylotrophic yeast Hansenula polymorpha," Biosensors and Bioelectronics, vol. 20, no. 7, pp. 1285-1290, 2005.

[23] O. Smutok, K. Dmytruk, M. Gonchar, A. Sibirny, and W. Schuhmann, "Permeabilized cells of flavocytochrome $b_{2}$ over-producing recombinant yeast Hansenula polymorpha as biological recognition element in amperometric lactate biosensors," Biosensors and Bioelectronics, vol. 23, no. 5, pp. 599-605, 2007.

[24] D/L-Lactic Acid, B-Biopharm GmbH, Darmstadt, Germany, http://www.mykotoksiner.dk/ProSmart/dox/PDF/E1112821_td .pdf.

[25] C. Lin, S. Chen, G. Kou, and C. Kuo, "An enzymatic microassay for lactate concentration in blood and hemolymph," Acta Zoologica Taiwanica, vol. 10, pp. 91-101, 1999.

[26] Lactate-Liquizyme, Egyptian Company for Biotechnology, Cairo, Egypt, http://www.spectrum-diagnostics.com/data/ Lactate-Liquizyme.pdf.

[27] "Lactate SCOUT, SensLab GmbH Leipzig, Germany," http:// www.senslab.de/.

[28] "Lactate Assay", The University of New Mexico, Albuquerque, NM, USA, http://www.unm.edu/ rrobergs/LactateAssay.PDF.

[29] K. V. Dmitruk, O. V. Smutok, M. V. Gonchar, and A. A. Sibirnyǐ, "Construction of flavocytochrome $b_{2}$-overproducing strains of the thermotolerant methylotrophic yeast Hansenula polymorpha (Pichia angusta)," Mikrobiologiia, vol. 77, no. 2, pp. 213-218, 2008. 

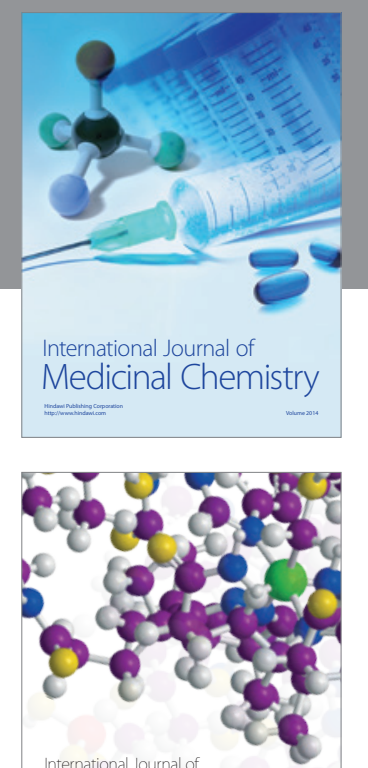

\section{Carbohydrate} Chemistry

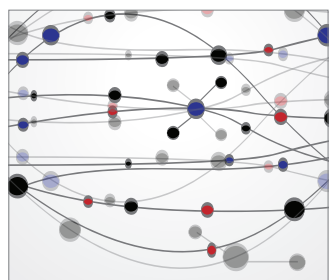

The Scientific World Journal
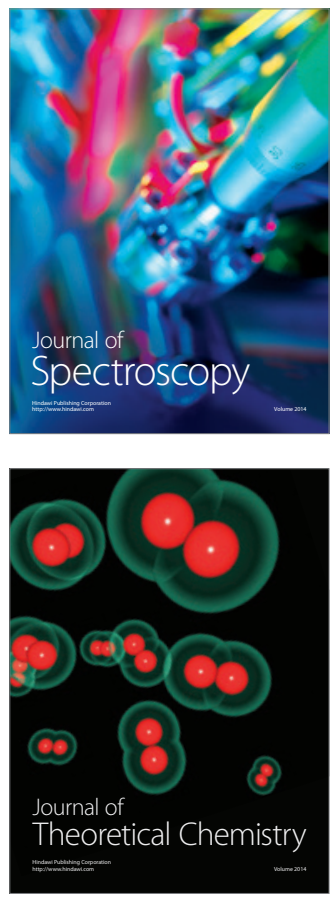
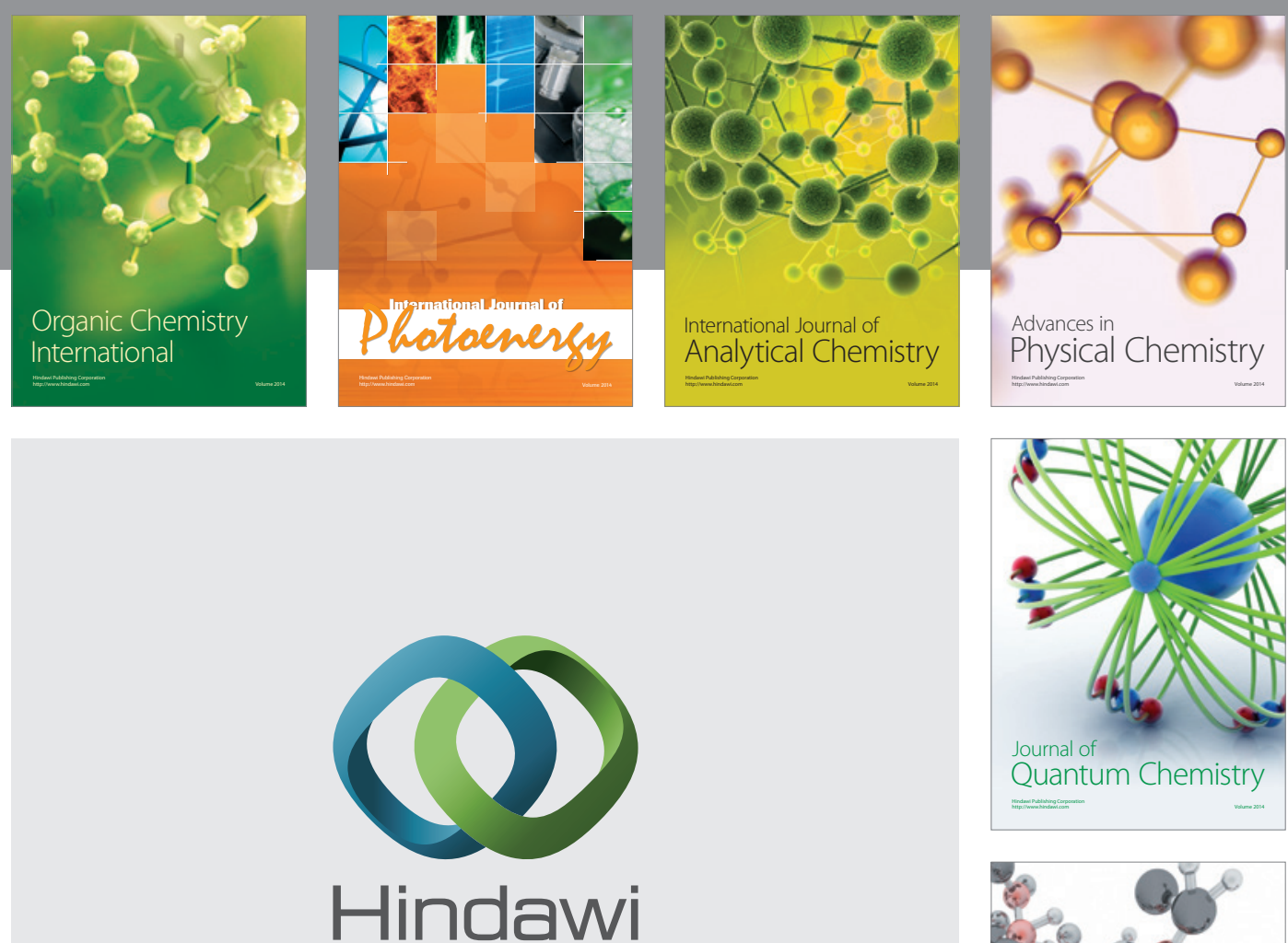

Submit your manuscripts at

http://www.hindawi.com

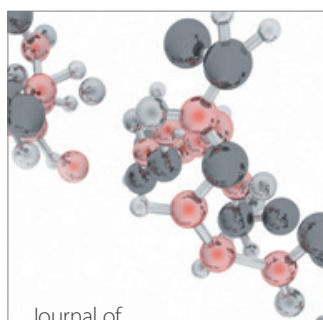

Analytical Methods

in Chemistry

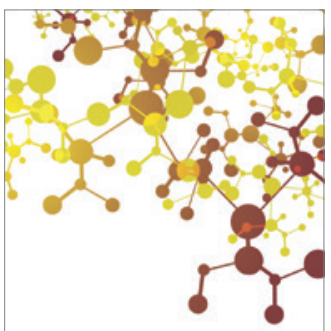

Journal of

Applied Chemistry

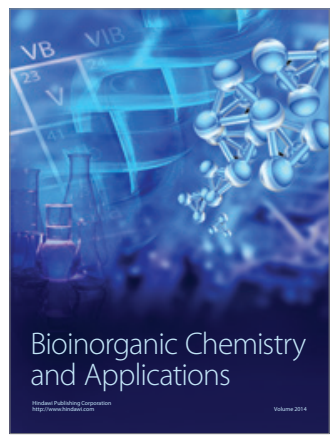

Inorganic Chemistry
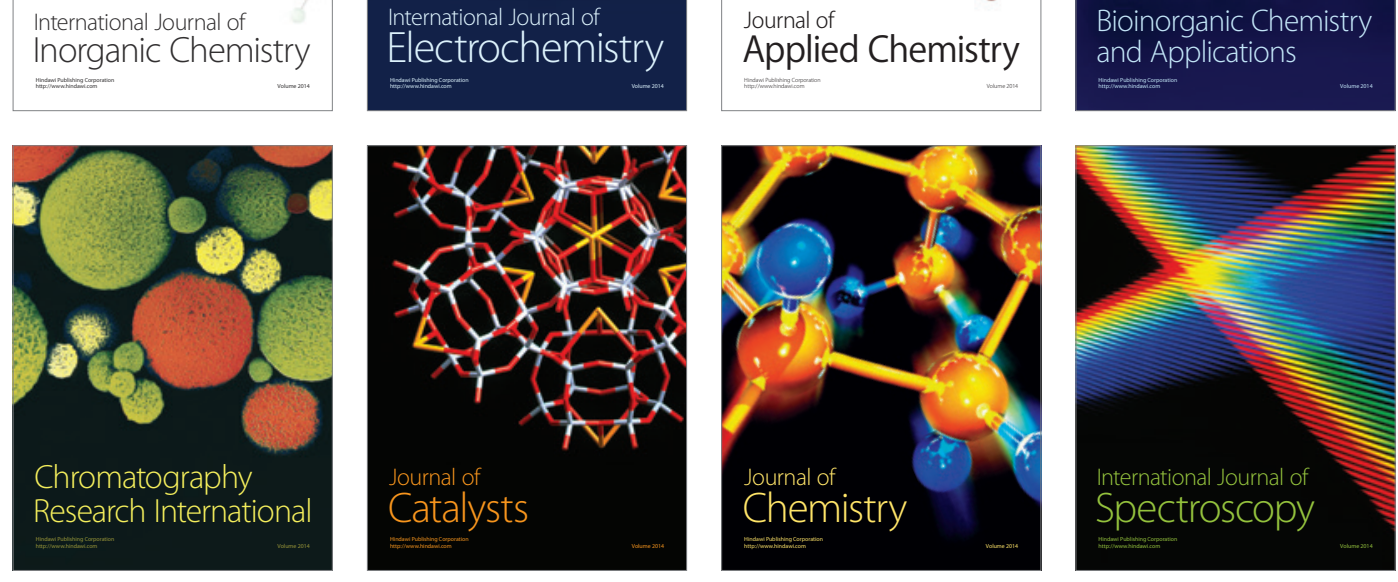